Sociological Forum, Vol. 24, No. 3, September 2009 (@ 2009)

DOI: $10.1111 /$ j.1573-7861.2009.01119.x

\title{
Social Distance and Affective Orientations ${ }^{1}$
}

\author{
Nedim Karakayali ${ }^{2}$
}

\begin{abstract}
Most groups have social distance norms that differentiate "us" from "them." Contrary to a widespread assumption in the sociological literature, however, these normative distinctions, even when they are collectively recognized, do not always overlap with the affective orientations of group members in a uniform manner. Relations between normatively close members of a group are not always warm and friendly, and normatively distant groups can sometimes be an object of reverence and love. In this study, a typology of five different ways in which normatively distant groups can be perceived is presented: as competitors, allies, symbols of otherness, saviors, and ambivalent figures. Each type tends to emerge under certain circumstances and triggers different affective orientations. This typology is not a substitute for a general theory, but it aims to provide preliminary insights for investigating why affective orientations toward normatively distant groups take different forms and, more generally, to motivate further inquiry into the relationships between different dimensions of social distance.
\end{abstract}

KEY WORDS: affectivity; emotions; social distance; stranger; triadic relations; xenophobia.

\section{INTRODUCTION}

How does social distance influence the affective content of social relations? More specifically, what different affective orientations might the members of a group display toward groups they consider as distant from their own? At least according to one frequently adopted perspective in the literature, such a question is essentially superfluous. From this point of view, strong affective bonds are a sign of social proximity and relatedness. When social distance increases, relationships tend to lose their affective content or, worse, negative affections dominate the relationship. ${ }^{3}$ In short, it is suggested that there is a linear relation between distance and affectivity; social distance is more or less identical to affective distance.

There have, of course, been other conceptions of social distance that do not reduce it to affective distance. Beginning with Simmel's (1950) and Park's

${ }^{1}$ I thank my colleague Dr. James Alexander for reading and commenting on an earlier version of this article.

2 Department of Political Science, Bilkent University, 06800 Bilkent, Ankara, Turkey; e-mail: nedim@bilkent.edu.tr.

${ }^{3}$ For some of the most explicit statements of this observation in the classical literature, see Bogardus (1941), Weber (1968:11-14), and Wood (1934:9). 
(1924) writings, sociologists have emphasized other-normative, interactive, and cultural - aspects of the concept (more on this in the next section). But even those scholars who view social distance as a complex category consisting of multiple dimensions tend to subscribe to a linear model when it comes to analyzing the relationships between its different dimensions. We can trace this linearity assumption all the way back to one of the first users of the concept, Gabriel Tarde (1962), who suggested that as the degree of imitation between two groups increases, there builds up more cultural similarity and, therefore, more social proximity between them. Several decades later, echoing Tarde, Homans (1950) argued that positive affections between people would increase with increased interaction. Applying the same logic to the closely affiliated concept of social ties, Granovetter (1973:1361) states that "the strength of a tie is a (probably linear) combination of the amount of time, the emotional intensity, the intimacy (mutual confiding) and the reciprocal services which characterize the tie." In short, in the sociological literature, it is a widespread expectation that while in the short run there might be some discrepancy between the dimensions of social distance, "[o]ver the long run," these dimensions are likely to "cluster so that there is but one dimension of social distance" (Kadushin, 1962:520).

The truth of the matter, however, is that the very same "gap" that Marsden and Campbell (1984) have identified in the conceptualization of "social ties" also exists for "social distance." We know very little about the interrelationships between the different indicators that have been used to measure social distance. The assumption that there must be a linear co-variation between different dimensions of social distance is just that - an assumption.

Yet, as I will try to demonstrate in this article, there is much empirical evidence that suggests that nonlinear associations between affective, normative, interactive, and cultural dimensions of social distance might last for very long periods. In fact, in some cases, this nonoverlap might be a precondition for the relationship to exist.

If so, then the question becomes under what circumstances different aspects of distance vary linearly, and under what other conditions there are nonlinear relations. In this article, I tackle a specific subset of that broad question: Under what conditions does affective content of the relations between groups that normatively view each other as "strangers" take on a positive or negative value?

In what follows, I will first outline the different dimensions of social distance. Then, focusing particularly on the relationships between affective and normative aspects of social distance, I will try to develop a preliminary typology based on five major forms in which a socially distant member of a group might be perceived by others: as a competitor, an ally, a symbol of otherness, a savior, and an ambivalent being. Although I do not suggest that these types are mutually exclusive, the last type seems to be unique to modern societies, and it might already be going through a transformation since 9/11. Nevertheless, each type tends to emerge under certain circumstances and triggers different 
emotional orientations. Some of these types are quite rigorously studied as separate cases and partly overlap with different models of stranger-relations in the sociological literature. Surveying them as a whole, however, might enable us to identify some of the basic tendencies that underlie the formation of diverse affective orientations toward normatively distant groups - a point that I will elaborate on in the conclusion.

\section{DIMENSIONS OF SOCIAL DISTANCE}

Social distance is generally understood as a uniquely sociological concept, irreducible to spatial or biologic (genetic) distance. Especially in recent decades, research on technological ties has shown that people can experience social distance and proximity without being "co-present" in the same physical space (Cerulo, 1997; Chayko, 2002; Katz and Rice, 2002; Meyrowitz, 1997). In a somewhat similar vein, one constant theme in the literature on "postmodernity" has been the decreasing significance of locality and spatial constraints - what Harvey (1989) calls "annihilation of space through time" — as a result of the changes in economy and technology in the twentieth century. But even those scholars who point out that spatial and biologic distance might interact with social distance tend to agree that the concept should be treated as an autonomous variable (Bourdieu, 1999; van den Berghe, 1987). Beyond this general agreement, however, there seems to be at least four distinct ways social distance is defined and utilized by social scientists. Let me briefly highlight these four conceptions that build on the affective, normative, interactive, and cultural aspects of social distance.

\section{Social Distance as Affective Distance}

This conception is based on the idea that those who are socially close to us are those we feel close to, and vice versa. The most popular utilization of this conception can be found in the Bogardus Social Distance Scale, ${ }^{4}$ devised by Emory S. Bogardus (1925), according to whom, mutual sympathy and affectivity are the key elements of social distance: "Where there is little

\footnotetext{
4 The Bogardus Social Distance Scale aims to measure how much social contact the informants (from one social group) are willing to have with members of other specific social groups. With this aim in mind, Bogardus (1925) used a questionnaire consisting of a set of seven questions (which were later revised and expanded). The informant is asked whether s/he would be willing to interact with the members of another specific group in one of the following forms, which can be seen as different levels of closeness/distance: (1) marry/have as a kin; (2) be friends; (3) have as a neighbor; (4) work together; (5) accept as a co-citizen (or "acquaintance"); (6) accept as a visitor in his/her country; or (7) does not accept at all within the borders of his/her country. The Bogardus Scale is assumed to be a "cumulative" scale in the sense that answering "yes" to a question at one level also implies a positive answer to all the other questions at the "lower" levels. For a critical history and different versions of the scale, see Ethington (1997).
} 
sympathetic understanding, social farness exists. Where sympathetic understanding is great, nearness exists" (Bogardus, 1941:106).

It is crucial to note here that such a conception treats social distance essentially as a subjective category. The Bogardus Scale, for example, records the subjective attitudes and feelings of the members of a group toward other groups. Bogardus (1947:306) himself maintains that "[i]n social distance studies the center of attention is on the feeling reactions of persons toward other persons and toward groups of people."

It would be quite vacuous to conceptualize social distance without any reference to subjective attitudes and emotions; however, there is an almost unsurpassable logical difficulty in treating social distance exclusively as a subjective category. If an individual is to develop specific "emotional reactions" toward other groups, s/he should already be able to identify those groups as distinct categories. The Bogardus Scale, for example, is built on the implicit assumption that informants have a general, collective understanding of who does not belong to their own group when they answer a question like: "Would you (as member of group A) like to live in the same neighborhood with a member of group B?" In effect, what the Bogardus Scale measures is what the members of a group feel about another group that they already perceive as being distant/distinct from their own group. All this indicates that there must also be an "objective" or "structural" aspect of social distance.

\section{Social Distance as Normative Distance}

As Kadushin (1962:518) points out, already in Simmel's work there were allusions to the possibility of treating social distance as "an objectively observable quantity which varies from one social structure to another," and about which there exist "consciously expressed norms." ${ }^{5}$ Understood this way, a normative social distance system can be seen as a set of collectively recognized norms about membership status in a group. These norms differentiate "us" from "them" - either through clear-cut divisions or in a gradual form-and specify what kind of relations with what kind of people are "acceptable." Kinship systems are probably the most obvious examples of such normative-objective systems of social distance. In addition to kinship, modern social formations involve multiple systems of social distance where a host of different criteria can be used to define who "belongs" and who does not (Simmel, 1955).

Whatever different forms they might take, however, all normative social distance systems distinguish between different degrees of membership to a group. It may be argued that as long as these distinctions overlap with the subjective feelings of the members, they "work" well. It is also quite likely that

${ }^{5}$ Durkheim (1964) also views social distance as an objective category (Hammond, 1983). For a comparison of Simmel's and Bogardus's conceptions of social distance, see Ethington (1997). 
if there is a serious discrepancy between what the members feel and what the normative system dictates, the system, if not "the group," might eventually dissolve. But, as I will try to show in this article, we have no reason to assume that such an overlap always and necessarily occurs.

\section{Social Distance as Interactive Distance}

A third dimension of social distance concerns how frequently two groups interact with each other. As Kadushin (1962:519) summarizes it, "[i]nteractive distance is the degree of actual interaction and need not match the normative prescriptions" (see also Warner and DeFleur, 1969). In the recent literature, the most sustained analysis of interactive distance was performed by scholars who adopt a network perspective. In Granovetter's (1973) well-known work, for example, the frequency and length of interaction are used as two major criteria for deciding about the weakness or strength of a social tie. Not surprisingly, interactive social distance also has a central significance in research on the social consequences of Internet use (Chayko, 2002; Katz and Rice, 2002; Meyrowitz, 1997).

\section{Social Distance as Cultural and Habitual Distance}

Gabriel Tarde (1962) was the first sociologist to propose that the distance between two groups - especially two classes - can be derived from the degree of imitation that exists between them (see Poole, 1927). In the subsequent literature, the emphasis seems to have shifted to the overall result of imitative processes, that is, to cultural similarities or to what some scholars call "psychocultural distance" between two groups (Szalay and Maday, 1983). In the contemporary literature, the most well-known use of cultural and habitual distance was developed by Pierre Bourdieu (1990), who proposed that social groups and classes can be mapped on a multidimensional "social space" on the basis of the types and volume of "capital" they possess. World system theorists use a similar approach in distinguishing between the "center" and "periphery." In Wallerstein's work, the emphasis is on economic and technological similarities, but, as Cerulo (1993) points out, one might also view these distinctions in terms of similarities and differences in the use of "national symbols" (see also Balibar and Wallerstein, 1991).

\section{BEYOND THE LINEAR MODEL: SIBLING RIVALRY AND XENOPHILIA}

Since the very beginning, then, the conceptualization of social distance has involved multiple dimensions. As I noted earlier, however, little attention 
has been paid to the interaction between these dimensions, and it is often readily assumed that they are interrelated in a linear fashion. There are, nevertheless, many observations in the literature implying that each aspect of social distance is partly independent of the others. In this section, I briefly discuss two situations in which the interaction between the normative and affective dimensions of social distance cannot be accounted for by a linear model. The first is when negative emotions, rivalry, hostility, and even violence erupt among the members of a group who are normatively defined as close; the second is when members of a group develop highly positive affections toward outsiders and strangers, sometimes even at the expense of those who are socially close to them.

The most obvious and extreme example of intense negative emotions between close members of a group is murderous conflicts between first-degree kin: fratricide, sororicide, patricide, matricide, and the like. In Western culture, these phenomena find their most paradigmatic expressions in the stories of Abel and Cain, Romulus and Remus, and Oedipus Rex.

That such murderous conflicts between close kin are often narrated in myths is quite remarkable. This, of course, does not necessarily mean that they are pure fantasies. There are many empirical examples, both from Western and non-Western societies, that testify to the presence of such conflicts (Davis, 2000), which is not so surprising since socially close members of a group often share similar desires and they often compete for similar resources-inheritance, power, sexual partners, and so forth-in the same environment. This is what Bourdieu (1977:39) seems to have in mind when he writes that "the closest genealogical relationship, that between brothers, is also the point of greatest tension."

Many social scientists have noticed this tendency. Simmel (1971a:147), for example, argued that a "trace of strangeness" is not absent from even the most intimate relationships. In a similar fashion, Freud wrote: "The evidence of psychoanalysis shows that almost every intimate emotional relation between two people which lasts for some time-marriage, friendship, the relations between parents and children - contains a sediment of feelings of aversion and hostility, which only escapes perception as a result of repression" (Freud 1985:130).

Following Freud's lead, Anton Blok (1998) has argued that "narcissism of small differences" leads to violence and tension between both culturally and normatively proximate groups - for example, between neighbors and friendsrather than between significantly distant groups. Building on ethnographic data, he further suggests that "great differences" and clearly defined distinctions and hierarchies might often function as a source of stability and peace, rather than intense violence. Incidentally, some of the most violent civil wars in contemporary history-in Bosnia, among others - seem to lend support to Blok's arguments.

But perhaps the most radical and well-known theory in this context is developed by René Girard (1987), who argues that "desire" spreads out in a 
collective like an epidemic through mimesis, leading to violent rivalry. Such violence among brothers, according to Girard, was more widespread in earlier human history, and myths are remnants of this violent past. Although it is hard to ascertain the truth of this hypothesis, Girard is probably justified in claiming that one of the major reasons such violence does not erupt more frequently has much to do with strict prohibitions against "sibling rivalry" and, more generally, against rivalry between group members in most cultures. ${ }^{6}$

Returning to the second case - that is, "xenophilia" - we need to stress that it has often been overlooked in the sociological literature that strong emotional reactions toward strangers might also have a friendly nature. To begin with, we can talk about the case of the "good stranger" who elicits equally strong emotional reactions as the "bad" stranger. The story of Ruth, the Moabite woman who joins the Israelites and unconditionally accepts their God, is a striking example. As Kristeva (1991:72) points out, Boaz's words in the Old Testament seem to imply that Ruth's reward is exceptional indeed: "May Yahweh reward you for what you have done! May perfect recompense be made to you by Yahweh, the God of Israel, to whom you have come, to find shelter beneath his wings" (Ruth 2:12). Kristeva (1991:73) suggests that "[o]ne cannot help emphasizing ... that Ruth's merit will be more sound than that of Abraham, and therefore worthy of a perfect reward. Could this be because Abraham left his father's house in answer to a call from God, while Ruth the foreigner did it on her own initiative?"

In addition to the example of the "good stranger," the "convert" who is more loyal to the group than its native members, we can also consider exoticism as another case in point. Especially in its modern forms, however, exoticism as a form of xenophilia is not necessarily devoid of self-interest. The fascination of eighteenth- and nineteenth-century European writers with the Orient, as Edward Said (1991) has pointed out, did not necessarily preclude a desire for domination. Several authors have observed that much of Orientalist writing involves a mixture of political and sexual desire for domination. As Todorov points out in his analysis of Pierre Loti's work, exoticism can easily be "inverted to become nationalism, and xenophilia becomes xenophobia" (Todorov, 1993:318). Thus:

\begin{abstract}
the exotic novel and the colonial novel can coexist so easily in the same author and during the same years, whereas their intentions seem so contradictory: the one glorifies foreigners while the other denigrates them. But the contradiction is only apparent. Once the author has declared that he himself is the only subject on board and that the others have been reduced to the role of objects, it is after all of secondary concern whether these objects are loved or despised. (Todorov, 1993:322-323)
\end{abstract}

Whatever the historically contingent peculiarities of European fascination with the Orient might be, these observations should come as no surprise. That

${ }^{6}$ In a very different domain, contemporary evolutionary biologists have shown that there are significant limitations to the association between "altruistic" behavior and genetic affinity. Thus, in his highly popular book on neo-Darwinian theory, Dawkins (1976) devotes two chapters to the issue of rivalry between parents and offspring, and between siblings. 
xenophilia should be a form of disinterested love is an assumption that follows from the linear model - where love toward "distant" people appears as an exceptional form of "self-sacrifice." If the linearity assumption is dropped, positive bonds with strangers should appear as one possible strategy among many for the investment of affective energies, and we have, then, no reason to expect them to be devoid of self-interest. ${ }^{7}$

\section{INVESTIGATING HOW RELATIONS WITH NORMATIVELY DISTANT GROUPS CAN TAKE DIFFERENT FORMS: A TYPOLOGY}

We are now ready to tackle the main problem of this article. If there is no fixed relation between normative social distance and affective orientations, then the question becomes under what conditions does this or that type of affective orientation develop between normatively distant members of a group. And, no doubt, of special concern to most social scientists is to understand how these orientations take on either a friendly or inimical form.

One fruitful way to approach that question is to look at the different types of relations that the members of a society might form with those individuals they perceive as belonging to a normatively distant group. Following Simmel (1971a), I will call these "normatively distant" members "strangers." Strangers are not simply outsiders but are perceived as being "distant" from the rest of the group in some fundamental sense; they are, in Simmel's words, perceived as lacking a "vital substance" that others possess. Thus, although strangers can be "near" to the group in other dimensions of social distance, their normative distance looms large and overshadows their nearness, leading to their identification as extraneous elements in the group. This situation might be temporary (as in Schutz's examples below), but it might also last for many generations.

In this article, therefore, I do not exclusively associate the "stranger" with any particular group. I use it in the sense of a certain social position that can be filled by many different groups. It may be true that the category of the stranger is often occupied by those ethnic and racial minorities in a society who have immigrated to this society from elsewhere. The most classical examples of the stranger in the sociological literature, such as the European Jews and Gypsies, and, to a lesser extent, immigrant groups in North America and elsewhere, fit this definition. However, not all strangers can be defined in ethnic or racial terms. Metics in Ancient Greece, for example, did not constitute and were not perceived as an ethnic group (Whitehead, 1977), nor was the aubain, that is, the "outcast" peasant who took refuge in a feudal estate other

${ }^{7}$ Many social scientists have pointed to the strategic role of positive bonds with strangers. As Bourdieu (1977:57) puts it in the particular case of selection of spouses, if marrying someone from one's close circle has the advantage of "security," marrying strangers might entail "alliance and prestige," and this choice "is posed anew with each marriage." I will elaborate further on this point below, in my discussion of alliances with strangers. 
than his/her original estate in medieval Europe, always seen as belonging to a particular ethnic group (Kristeva, 1991). In fact, some scholars, such as Alfred Schutz, have included in this category such diverse groups as "[t]he applicant for membership in a closed club, the prospective bridegroom who wants to be admitted to the girl's family, the farmer's son who enters college, the citydweller who settles in a rural environment, the 'selectee' who joins the Army, the family of the war worker who moves into a boom town" (Schutz, 1971:91).

The typology I present below lists five different forms in which the members of a society might perceive and affectively orient themselves toward groups they consider as being normatively distant from their own group. The underlying structure of the typology is such that, in the first two types - competition and alliance - what is at stake are material resources and political power. In the remaining three types, in contrast, the emphasis is on the "symbolic" significance of the stranger. These divisions are essentially analytic. I do not claim that these types are mutually exclusive. Nor do I claim that the list is exhaustive. Nevertheless, I believe it provides a good starting point for exploring the complex nature of the relations between normative and affective social distance.

\section{The Stranger as a Competitor}

One major observation in the sociological literature is that negative emotions toward strangers follow from conflicts over scarce resources and political power. This thesis can be found in the works of contemporary scholars who study ethnic and racial conflicts from a historical/materialist point of view. The proponents of this approach have diverse theoretical orientations, including Marxian, Weberian, and sociobiological perspectives (Bonacich, 1973; Rex and Mason, 1986; Van den Berghe, 1987; see also Hechter, 1978).

Needless to say, competition for resources (whether natural or socially constructed) is a very widespread phenomenon and can take a whole range of different forms. The important point for our concerns here is that normatively distant groups are not always perceived as competitors. One obvious precondition for this to happen is that the competing groups must be relatively free to pursue the same goals. Political and legal barriers (such as slavery) can hinder the development of any significant competition between two groups. As Tocqueville (2002) observed, prior to the U.S. Civil War, African Americans were seen as economic or political rivals not in the South, but in the North where slavery was abolished. In addition to such barriers, there can be all sorts of other mechanisms (such as niche specialization) that might hinder the development of competitive relations between normatively distant groups (van den Berghe, 1987).

But perhaps an equally important precondition is that each competing group must be highly cohesive and solidaristic, which often occurs if the groups are based on kinship and ethnic ties. In this context, the case that is studied most closely is middlemen minorities who have been a target of violent 
attacks in many societies. In her oft-cited study, Edna Bonacich (1973) has argued that such violence builds up over time as a result of the peculiar structure within which the interaction between middleman minorities and the host society takes place. In response to their initial exclusion from the society at large, members of the middlemen community develop strong solidaristic ties. They invest forcefully into whatever venues are open to them, which often allows them to be economically successful. In return, this success generates even more distance and envy. Eventually, the mutual intensification of success and envy turns into a "vicious circle." Following a similar line of argumentation, van den Berghe (1987:144) adds:

Since MMs [middleman minorities] deal more directly and frequently with the masses than the upper class, and since many of these encounters take place in a context of cultural differences and misunderstandings and involve conflicts of interest, it is little wonder that MMs become primary targets of hostility by the native masses.

Such negative emotions - which might sometimes have a mutual or reciprocal character-can function as conscious or unconscious strategies for excluding the other from competition: "Ethnic sentiments can be instantaneously mobilized in the defense of interests or even hysterically whipped up in response to imaginary threats" (Van den Berghe, 1987:156).

The "competition model" provides important insights about material interests that might underlie affective orientations toward normatively distant members of a group. It has, however, two significant shortcomings. First, in much of the analysis mentioned above, the absence of affective bonds between strangers and natives seems to be conflated with the presence of intense negative affections. The fact is, however, that, for example, middlemen minorities might exist in a society as a marginal group for long periods of time, interacting regularly with others, even if mostly in a formal and distant manner. It is almost always in periods of rapid social change that they become targets of downright hostility. In other words, negative affections tend to materialize only under certain circumstances. This means that "competition" alone might not be the sole factor in triggering such affective responses. I will return to the significance of this point later.

Second, according to the "competition model," negative emotions and stereotypes essentially play a "secondary" or "ideological" role. They are either "superstructural" effects of more primary struggles, or functional strategies for securing material resources. Therefore, in contrast with the approaches we will discuss after the next section, the proponents of the "competition model" have paid little attention to the social-psychological mechanisms that might underlie such emotions.

\section{The Stranger as an Ally}

It may be true that competition between two normatively distant groups often leads to antagonistic relations. However, as Simmel (1971a) pointed out a 
long time ago, sometimes social distance can also play a productive role: the members of a group can form certain relations with normatively distant groups that they cannot form with each other (Karakayali, 2006). The stranger, under certain circumstances, can operate as an ally as much as a competitor.

But what exactly are those circumstances that lead to alliances between normatively distant groups? In fact, there seems to be three distinct ways such alliances can be formed. The first one, which concerns cross-cultural alliances, was observed by both Simmel (1971b) and Durkheim (1964) a long time ago. Such alliances, they argued, often presuppose an increase in the size of a society, combined with an increase in the division of labor: "differentiation and individualization loosen the bond of the individual with those who are most near in order to weave in its place a new one - both real and ideal - with those who are more distant" (Simmel, 1971b:256; see also Hammond, 1983). For example, the more stratified the society is and the more sharply class distinctions stand out in it, the more the members of particular classes will tend to develop a sympathy for people in other groups who occupy a similar position in the social structure rather than other members of their own society. The "supra-nationalism" of the European nobility and the "internationalism" of some working-class movements are among the most salient examples (Simmel, 1971b:253). In recent years, many scholars have observed another factor that seems to encourage such alliances, namely, the existence of a medium (such as the Internet) that increases the possibility of interaction between individuals with similar social positions and "mental" dispositions despite social or geographic barriers (Chayko, 2002; Meyrowitz, 1997).

The second circumstance involves alliances between strangers and the ruling elites in a society. Lewis Coser (1972) has paid much attention to the conditions under which such alliances are forged. One precondition for such alliances, Coser points out, is that the social divisions in a society must be going through a rapid transition, leading to a widening gap between the ruling elites and the "native" subjects they rule. The rulers can no longer depend on their native subjects because they fear that those subjects might either retaliate or attempt to seize power. Instead, they ally themselves with strangers who do not have a foothold in the society and who, therefore, are more likely to be loyal to them. Coser's analysis is supported by numerous historical cases: non-Muslim children who were recruited for the elite staff and army of Ottoman rulers, the Court Jews of Baroque Germany, the "slave soldiers" (Mamelukes) used by Islamic rulers of Egypt, Jewish advisors who were employed in the Muslim courts of medieval Spain, Swiss mercenaries who served French kings, Praetorian Guards of Roman emperors, and the "eunuchs" who served Chinese emperors (Coser, 1972:575). The pattern identified by Coser also seems to repeat in colonial contexts where colonial rulers employ subjects they exported from elsewhere as "middlemen" in order to avoid direct confrontation with the local population (Leighton, 1979).

Finally, strangers can also form alliances and mutually beneficial contacts with estranged members of a group or with nonprivileged classes, although especially the latter are relatively rare and little studied. A striking analysis of 
this type of alliance was provided by Hannah Arendt (1974), who shows how the Jewish salons played a catalyzing role in the emergence of a new class (i.e., the bourgeoisie) in late eighteenth-century Germany. The salon of Rahel Varnhagen - a Jewish woman whose ties with her community were severed but who was not fully accepted in the German society - constituted "a socially neutral place where all classes met and where it was taken for granted that each person would be an individual" (Arendt, 1974:38). Rahel's salon, like many others in Berlin, drew those individuals who had escaped the centripetal forces in society and who were in "exile" from their group, such as the nobleman Finckenstein to whom Rahel was engaged (Arendt, 1974:39). Rahel's case is an example of subtle and intimate alliances between strangers and estranged or underprivileged members of a group. The relations that were forged between "commoners" on the Hawaiian islands and Captain Cook's crew might also be cited as another striking example from a very different context (Sahlins, 1985). The history of religious movements involves similar examples (Weber, 1952; Zeitlin, 1984). Paul's (of the Christian tradition) audience, as Kristeva (1991:78) notes, "came from that part of the population that was "marginal to the civic body' [of the Roman Empire]."

The affective dynamics of alliances with strangers is a relatively little studied topic in the sociological literature. The existing data seem to indicate that in terms of affective orientations, alliances with strangers do not have a homogeneous outcome. As Coser (1972) suggests, the alliance of ruling classes with strangers might not immediately give way to an increase in affective ties because the alliance remains conditional on preservation of affective distance. The stranger as an ally, in other words, remains useful as long as $s /$ he is a loyal "servant." As the isolation of the ruler from the rest of his or her subjects increases, however, the loyal servant might eventually turn into a best friend. The strong affection and trust that Chinese emperors, during certain periods, have reportedly developed toward "eunuchs" is one such example (Mitamura, 1963). In a somewhat similar vein, alliances between the estranged members of a group and strangers might result in growing sentimental ties, as in the case of the nobleman Finckenstein and Rahel Varnhagen.

As a corollary, it is important to note that in their alliances with ruling groups as "servants of power," strangers often occupy a passive position, but in alliances with estranged members and lower classes or, more generally, in alliances where affective ties are strong, strangers seem to play a more active and transformative role. In other words, in the former case, they basically serve the establishment of a social division, whereas in the latter, they catalyze the emergence of divisions (more on this point in the conclusion).

\section{The Stranger as a Symbol of Otherness}

That negative affective orientations toward strangers can develop quite independent of competition for scarce resources has been emphasized by 
contemporary scholars who focus on the social-psychological or symbolic dimensions of stranger-relations. One of the most obvious examples of this approach can be found in Levine (1979:29-30), who utilizes Freud's theory, which links aversion toward strangers to assertion of self-love, referring to the following passage from his essay on "Group Psychology."

In the undisguised antipathies and aversions which people feel towards strangers with whom they have to do we may recognize the expression of self-love - of narcissism. This self-love works for the self-assertion of the individual, and behaves as though the occurrence of any divergence from his own particular lines of development involved a criticism of them and a demand for their alteration. (Freud 1985:131)

Here, aversion toward strangers is understood as a psychological mechanism and there is no reference to an underlying material struggle. The only concern is the preservation of "self-identity": xenophobia springs forth from "selflove."

Let us briefly note, however, that Freud's analysis is not based on a dyadic opposition between the self and the other. As Borch-Jacobsen (1988) shows, implicit in Freud's theory of narcissism is the idea that the "self" is already an "other" - has to be an "other" - in order to be loved (see also Blok, 1998). In fact, in "Group Psychology," Freud (1985) anticipates a triadic conception of stranger-relations, where the "self" or the "group" confronting the "stranger" is viewed as a "divided entity" and not as a self-contained unity. This triadic conception has also been utilized in many classical works in the sociological literature dealing with social deviance in general and the sources of negative reactions against strangers in particular.

Probably the best-known example here is Durkheim's (1982) theory that crime is not simply pathological and that the punishment of criminals plays an integrative function: the animosity felt toward the criminal as a "third party" holds the other members together and strengthens the moral ties among them. In a similar vein, Simmel (1971a) relates negative reactions toward strangers to internal conflicts among group members. The link that Simmel draws between internal rivalries in a group and negative reactions toward strangers can be observed in a widespread phenomenon, namely, the treatment of strangers as scapegoats. Simmel's argument is based on a frequently observed fact, namely, that scapegoating of strangers gains an impetus in times of crisis when a society is going through radical transformations and when the rival factions in a group begin to attack each other virulently. ${ }^{8}$ A somewhat similar observation can be found in Max Weber's work on polytheism and magic, where the fear from "religious aliens" is interpreted as following from doubts about the loyalty of the ancestral gods to the group. These doubts, in return, seem to be closely associated with doubts about the fidelity of the members of the group to the political association (Weber, 1964:15-18).

\footnotetext{
8 "From earliest times, in uprisings of all sorts the attacked party has claimed that there has been
} incitement from the outside, by foreign emissaries and agitators" (Simmel, 1971a:146). 
These classical sociologists anticipate René Girard's (1986) thesis that, throughout history, strangers have served as scapegoats to deflect potential conflicts between "brothers." A detailed discussion of Girard's theory, which explores the links between desire, violence, and the "sacred," is beyond the scope of this article. For our specific concerns here, however, the gist of Girard's observations can be summarized by the following comments of Freud: "[H]atred against a particular person or institution might operate in just the same unifying way, and might call up the same kind of emotional ties as positive attachment" (Freud, 1985:129-130). These observations suggest that hating - and perhaps even loving — a "third party" might function as a mechanism that strengthens affective bonds among the members of a group that might have otherwise dissolved due to internal conflict.

The phenomenon of scapegoating teaches us that hostile accusations toward strangers often have a nonrational and fantastic nature. This observation has led many social scientists to consider xenophobia as a symptom either of deeper social problems or, more generally, of a repressed fear from the "stranger within." 10 Most notably, using anti-Semitism as a basic example, Adorno et al. (1950) have argued that the stranger as a target of hostility is essentially a "substitute object" for the repressive social forces that the individual cannot confront directly. Such hostile reactions are "not so much dependent upon the nature of the object as upon the subject's own psychological wants and needs" (Adorno et al., 1950:609).

\section{The Stranger as a Savior}

Analyses offered by scholars such as Girard and Adorno contribute in important ways to our understanding of the links between xenophobia and psychosocial processes. The problem is that their analyses give us a one-sided picture: affective orientations in stranger-relations appear to be solely determined by the nature of the relations among "natives." When the latter set of relations turns sour and frustrating (or "repressive"), the former provides a kind of outlet for these frustrations. As such, stranger-relations appear to have no "positive" (i.e., transformative) effect whatsoever on the relations among the "natives."

${ }^{9}$ In fact, both Girard and Freud, albeit in very different ways, suggest that the collective "love" felt for a violently murdered victim whose death brings peace and stability to a group is at the origin of human culture.

10 Thus, despite their divergent approaches, both Adorno et al. (1950:609) and Kristeva (1991:182-192), along with many others, adopt the Freudian notion of the "uncanny" to conceptualize xenophobia and to draw support for their claim that the stranger operates as a "substitute" for a repressed object of fear. An uncanny object, for Freud (1973), belongs to a particular class of "frightening" objects that do not seem to constitute a direct threat to us but nevertheless send a shiver down our spine in an inexplicable manner. Such objects appear to us "uncanny" not because they are completely unfamiliar or new; rather, "[t]he uncanny is something which is secretly familiar, which has undergone repression and then returned from it, and that everything that is uncanny fulfils this condition" (Freud 1973:245). 
In this respect, the perception of strangers as saviors is almost a perfect counterpoint to their perception as a symbol of otherness. Such a perception is already implicit in the myths and legends of numerous societies "that mention the existence of superior and kindly beings beyond their own world" (Tuan, 1986:12). Many of these legends narrate the good results of encounters with strangers. The idea is not limited to ancient myths; many texts of the Enlightenment era (Willey, 1965) and contemporary films such as Kurusawa's Seven Samurai and Spielberg's E.T. repeat the same theme. As Mary Helms's (1988) synthesis of a wide range of historical and anthropological data indicates, however, the stranger as a savior is by no means just a legendary figure.

What are the conditions under which strangers can be perceived as saviors? There seems to be two interrelated reasons for such a development. The first reason is partly alluded to in Simmel's (1971a) work, where he pointed out that because strangers occupy a distinct position in a group, they can often accomplish certain vital tasks in the group that other, "native" members are less likely to accomplish. ${ }^{11}$ In this respect, one case that is well studied in the literature is the capacity of strangers to work as arbitrators in a group that consist of rival factions, mainly because the strangers are capable of preserving an equal affective and normative distance to all the factions (Colson, 1966; Simmel, 1950:216). Referring to the groups inhabiting the area between Lakes Malawi and Tanganyika in South Africa, Monica Wilson (1979:56-57) notes that:

\footnotetext{
$[O] n e$ people after another tell of how their chiefs came as strangers and were welcomed as benefactors. Before they came, authority did not extend beyond one village. They were welcomed because they brought "lordship" symbolized by fire; because they brought iron weapons and tools; cattle; and new crops ... [There were groups] who had no chiefs carrying off the son of a chief from elsewhere and establishing him among themselves to stop fighting. Order in society is, after all, one of the things men seek, and the outsider sometimes has the prestige which an insider lacks to maintain order.
}

One form in which strangers can take on the role of a savior, then, is by making practical contributions to a community, especially through arbitration, on the basis of partly the practical and partly the symbolic value attributed to their "distance." But there is also a second, and perhaps more striking, form in which strangers become saviors, namely, by providing spiritual guidance and esoteric knowledge, as "men of learning from afar" (Helms, 1988:94). This capacity is once again related to the distance of the stranger - in both a geographic and sociocultural sense - which, Helms (1988:4) suggests, follows from the widespread belief that "as one moves away from axis mundi one moves towards places and people that are increasingly 'different' and, therefore, may be regarded as increasingly supernatural, mythical, and powerful, the more distant they are from the heartland."

Especially in premodern societies, one way to tap into these alleged mythical powers was through long-distance travel. Upon their return home, long-distance travelers would often be viewed as possessors of esoteric

${ }^{11}$ See Karakayali (2006) for a detailed discussion of these "tasks." 
knowledge and endowed with prestige and honor. ${ }^{12}$ But these attributes would be all the more emphasized "in situations where long-distance specialists were ethnically foreign to the polity in which they lived and served" (Helms, 1988:94). There are so many examples of strangers who were respected as spiritual guides in the literature. Hausa and Dyula migratory traders in Africa, for example, "have traditionally served as administrative advisers, consultants, diviners, prayer makers, curers, and especially sellers of the reputedly most potent Muslim charms and amulets to royalty and commoners alike" (Helms, 1988:97). Nestorian missionaries enjoyed a similar prestige in western and central Asia (Helms, 1988:103-105). Jesuit fathers in China were yet "another supreme example of a group of foreigners of undoubted learning coming from a distant land who were imbued with an aura of the exotic by virtue of their foreignness and were accorded highest honors at a royal court as men of great wisdom and knowledge and as masters of specialized arts and crafts" (Helms, 1988:105). The spread of Christianity in the Roman Empire can also be cited as a relevant example here. As Sennett (1977:3) points out, when at the end of the Augustan age affective bonds among Roman citizens began to weaken and public life became a mere formality, some of these citizens sought "a new focus for [their] emotional energies, a new principle of commitment and belief," which they found in Near Eastern sects.

The stranger as a savior constitutes a striking contrast to the stranger as a scapegoat in many respects. In terms of the symbolic value attributed to "distance," in the former case, distance is associated with benevolence, wisdom, and objectivity; in the latter, with a threatening otherness. Again, in the former case, the stranger plays an active and transformative role, while in the latter, s/he turns into a passive victim. We can identify many cases where both types confront a society where affective bonds between socially close members of a group are in the process of eroding. However, while in the case of scapegoating, it is negative emotions such as hatred and fear that are rerouted toward the normatively distant groups, in the case of the savior, the stranger becomes an attractor of positive affections.

Why one or the other route is taken seems to depend on a host of factors and it is perhaps impossible to develop a general theory that encompasses all empirical cases. But the most conspicuous factor seems to be the nature of past relations between two groups. If there is a long history of conflictual relations as, for example, in the case of Jews, Christians, and Muslims, the chances of one group viewing the other as a savior seem to diminish. Strangers in the role of saviors tend to emerge when two groups have had little encounter in the past, such as the tribal groups and Muslim traders in Africa, or Jesuit fathers and Chinese rulers. Paradoxically enough, the less the group knows about the strangers and the fewer stereotypes it has about them, the better, it seems, are the chances for the strangers to be accepted as benevolent

12 It can be argued that a similar attitude persists in the modern world since being educated abroad - particularly in the West - is a source of prestige in many societies also today. 
figures. This lack of knowledge, especially in premodern societies, is closely associated with geographic distance. Numbers also seem to be a factor, since strangers in the role of saviors often consist of a few individuals, which perhaps reduces their chances of being perceived as a serious political threat (see, e.g., Wilson, 1979:52).

\section{The Stranger as an Ambivalent Figure}

The four types we have analyzed so far indicate that, potentially, a stranger might be a competitor as well as an ally; an object of hatred as well as of reverence. In fact, it is not unusual that such contrasting attitudes are present simultaneously in the same society. Middleman minorities, for example, have often been in a relation of competition with the local population, while they were allies with the ruling groups. The same is sometimes true for the strangersavior: "[f]oreign wise men, because they are sagacious, can also pose a threat to local men of knowledge," and hence be viewed as a symbol of otherness (Helms, 1988:108). On the basis of such observations, some scholars refer to "a persisting ambivalence underlying all stranger relationships" (Levine, 1979:30).

This assumption, however, should be carefully qualified. As Zygmunt Bauman (1991) has pointed out, while there might be some type of emotional and cognitive ambivalence in most stranger-relations, the conception of the stranger as an ambivalent figure - or, perhaps, more precisely, as an ambivalence-inducing figure - is predominantly a modern phenomenon.

It is, in fact, mostly in research on modern international migration that the ambivalence of the stranger is emphasized. At least since Marcus Lee Hansen's (1952) pioneering work on the topic, there has emerged a vast sociological literature that reiterates the thesis that immigrants and especially their children are caught between two cultures, that they have allegiance to two different sets of norms, that they are both insiders and outsiders, and so forth. This idea was first developed in the early twentieth century in the context of immigration to North America and it has since then been applied to numerous other contexts, particularly to postwar European societies (Karakayali, 2005).

How can we account for this metamorphosis in the conception of the stranger in the modern era? What conditions in modern society trigger the perception of the stranger as an ambivalent figure? It was again Simmel who first tried to propose an answer to that question, and much of the contemporary theorizing on the topic echoes his proposition.

It has sometimes been argued that Simmel's concept of the stranger is quite useless in the modern context, since he developed the concept on the basis of premodern cases (Harman, 1988). However, while it is true that Simmel's writings involve almost no reference to international migration in the late nineteenth century, he did in fact underline that "strangers in the original sense no longer exist today" (Simmel, 1990:227). The main reason for this 
change, however, has little to do with the characteristics of modern strangers; rather, it follows from a series of radical transformations in modern society, especially the growth of market economy and urbanization.

The gist of Simmel's argument, which he states in the context of the spread of money economy, is that in modern society, the contrasts that existed between natives and strangers are no longer so visible and easily sustainable (Simmel, 1990:227). This does not necessarily mean that there are no strangers anymore but, as he would reiterate in his well-known essay on metropolis, the relations between modern urbanites resemble stranger-relations in most aspects. Perin's (1988) work, where she shows how much neighbors in the contemporary United States doubt each other and avoid direct communication, implies that Simmel's observations are still valid today. To put it in slightly different terms, both strangeness and "nativity" become problematic and ambiguous notions in modern societies.

A similar argument is implicit in Weber's work on ancient Judaism, where he notes that, with the birth of monotheism and the invention of the notion of berith, one can no longer entertain the idea that social unrest and disunity are the outcome of magical processes, or a result of the conspiracy of strangers, but must realize that they are real risks engraved in the very nature of social and political relations (Weber, 1952:118). In the long run, the development of monotheism - which Weber seems to associate with a growing rationalization in religious and political domains - gives the members of the religiopolitical community an inclination toward "self-questioning" (Zeitlin, 1984). At the same time, with respect to strangers, the problem now is not so much how to exclude them from sacred/secret domains but how to turn them into loyal members of the group (Bodemann, 1993). We might even talk about a kind of "disenchantment of native-stranger division": as the "natives" begin to question themselves and the legitimacy of their political institutions, the stranger becomes a potential native who can be "integrated" to the group through the use of correct procedures. ${ }^{13}$

Simmel's and Weber's observations are repeated in numerous contemporary works on stranger-relations that emphasize the ethical, political, and philosophical difficulties involved in making clear distinctions in modern societies between the native and the stranger (Bauman, 1991; Derrida, 2000; Girard, 1986; Kristeva, 1991; Räthzel, 1995).

What is crucial for our concerns in this article is that a new type of affective orientation toward strangers seems to have arisen as a result of this double ambivalence about the "self" and the "other," which is not observable in

13 It might perhaps be possible to view these changes in stranger relations in parallel to another change in modern society identified by Foucault (1977): the shift from exclusionary toward disciplinary power, which targets pervasive surveillance of all individuals in society. In this disciplinary regime of power, as "deviance" is perceived as a disease that can be cured with correct methods, "normality" appears as an unstable condition that might turn into its opposite without proper discipline. 
the other four types of relations discussed above. This affective orientation can be characterized as a generalized anxiety.

Zygmunt Bauman (1991) has paid much attention to the sources of this anxiety in modern societies. At the roots of this anxiety is the well-known dilemma of modern culture: on the one hand, modernity constantly produces change and ambiguity; on the other, it involves a desire to cover up or eliminate this ambiguity by appealing to clear-cut distinctions between the self and the other, the inside and the outside, culture and nature, and so on. The interactive and spatial proximity of groups that are considered to be normatively distant, however, reveal the difficulty in sustaining such clear distinctions (see also Zerubavel, 1993). In effect, the stranger is not an ambivalent being, but $\mathrm{s} / \mathrm{he}$ is an "ambivalence-inducing"-or, perhaps, an "ambivalence-revealing"- - social category.

Analyses similar to Bauman's are quite widespread in the recent literature. In most of these studies (some of which are directly inspired by Bauman's work), anxieties about and aggression toward strangers are associated with the fact that the presence of strangers dismantles the taken-for-granted self-representation of the group. It is, for example, a widespread observation that immigration motivates debates and controversies about the "essential" characteristics of a nation. Verkuyten et al. (1995:258), for example, show how the presence of immigrants affects the conception of "Dutch identity" among the inhabitants of an ethnically mixed neighborhood in Rotterdam. Similarly, on the basis of her research in Germany, Nora Räthzel (1995:59) concludes that the "images of 'Ausländer' are threatening because they make our takenfor-granted 'identities' visible as specific 'identities,' depriving them of their assumed naturalness."

These studies imply a certain difference between the stranger as a scapegoat and the stranger as an ambivalent figure. In the case of scapegoating, the internal turmoil in the group precedes or is independent of the presence of the stranger, whereas in the latter case, the anxiety comes into existence because with the appearance of the stranger, the group can no longer perceive itself in the same way as before. However, as both Bauman and Adorno point out, the anxiety induced by the stranger in modern society can easily give way to the "uncanny" fear and hatred felt toward a scapegoat.

One final issue I would like to mention before ending this section concerns the developments in the aftermath of $9 / 11$. Is the conception of the stranger going through yet a new transformation in our time? While it is perhaps too early to give a clear answer to that question, three important changes are worth mentioning. First, since $9 / 11$, all over the globe, religious identity seems to have become the main criterion of normative distance. The distinction between "us" and "them," "inside" and "outside," seems to be reconfigured along religious lines. Second, given the heterogeneous and cosmopolitan nature of contemporary societies, this "outside" is becoming growingly unlocalizable and hard to pin-point, multiplying the "ambivalence" effect (Faist, 2002). Finally, as a corollary to these developments, a new paradigmatic type 
of the stranger emerges as a potential religiopolitical competitor, as well as an anxiety- and fear-inducing other (Huddy et al., 2005). In short, all the negative affective orientations identified in this article seem to become amalgamated in this new figure of the stranger as a "potential enemy," leaving little room for the more positive relations that have historically been formed with normatively distant groups.

\section{CONCLUSION}

I started this article by questioning the widespread assumption that there is a linear correlation between different dimensions of social distance. The typology I sketched out above indicates that this assumption, at least for two dimensions of social distance, is rather untenable. Such a typology, however, is far from providing a full-fledged theory about how dimensions of social distance relate to each other. Nevertheless, in concluding this article, I would like to offer one general proposition, some elements of which were already mentioned in the preceding sections: different affective orientations toward normatively distant groups seem to arise partly in reaction to ongoing social differentiation and conflicts between normatively close members of a group. There seems to be two diametrically opposed ways this can take place.

1. In societies with significant internal divisions and rivalry, normatively distant groups can play a "unifying role" by constituting either a common object of love or hate. The first option is exemplified by strangers as saviors, especially when they act as arbitrators, "spiritual guides," or "charismatic" leaders who offer hope, skills, and wisdom to a group in turmoil (Helms, 1988; Wilson, 1979). With respect to the second option, let us note that while competition for material resources and power might play a certain role in the development of negative affective orientations toward strangers, this option is most vividly exemplified by the stranger as a scapegoat. For it is especially in this case that stranger-relations constitute a domain into which the anger and hatred resulting from internal rivalry are reinvested. These two types, however, are not mutually exclusive. As in the case of middlemen minorities, they might easily merge into each other and the stranger might be perceived both as a competitor and as a symbol of otherness. As I have already underlined, we still need much more data to grasp under what conditions strangers become objects of love or hate but, in light of the limited number of cases we have analyzed, the nature of past relations, absence or presence of knowledge and stereotypes about the normatively distant groups, geographic distance, and numbers seem to be the most salient factors. 
2. At the opposite extreme, strangers can play a "divisive" role by constituting an alternative venue for the investment of affective energies for certain members of a group. Thus, new affective ties formed with strangers might either help preserve existing divisions between the members of a group or directly trigger and catalyze their emergence. The most obvious case here is that of the stranger as a "servant of power," who can become instrumental in the preservation of a division between a ruling elite and its native subjects, though not all such alliances give way to strong affective ties. In some other forms of alliances and in some versions of the stranger as a savior, however, the estranged members of a group who no longer "feel close" to others in their group might instead form affective bonds with other groups and cultures. Thus, stranger-relations constitute a domain for reinvestment of positive affections that can no longer be invested in relations with socially proximate members. As such, the stranger becomes an "escape-route" rather than a "scapegoat."

These two tendencies - which highlight the capacity of the stranger for both subduing and triggering social divisions, and for constituting both an object of love and hate-indicate that how people relate to socially distant groups is a function of how they relate to socially proximate members of their own society and vice versa. This implies a triadic rather than a dyadic-linear configuration. The two tendencies we have outlined are indeed just a specific subset of structural tendencies of triadic relations, first discussed by Simmel (1950), and further elaborated by Heider (1958) in his "balance theory."

However, while a triadic model can be a good starting point in developing a theory about the dynamics of social distance, the two structural tendencies outlined above are not meant to be a substitute for empirical research. What Lynn Chancer (1992) observes with respect to the "dynamics of power and powerlessness" might apply equally well to the dynamics of distance and nearness. A theoretical model that specifies the tendencies in a relationship is never enough to predict its exact outcome because this outcome "depends on a complex set of historical, social, and psychological circumstances that pull its tendencies in unpredictable directions" (Chancer, 1992:67).

In fact, the dynamic of social distance is even more complex than it seems since most of the cases we have analyzed indicate that the two tendencies outlined above often co-exist. For example, at any given time in a society, we are likely to observe that there is some internal differentiation and rivalry, which, along with other factors such as competition, motivate negative affective orientations toward strangers, just as there is perhaps some positive contact with strangers that triggers internal differentiation. This complexity becomes more visible when we shift our attention from premodern societies with limited social differentiation to modern societies. It seems that when social differentiation in a society goes beyond a certain threshold, rendering the distinction between social proximity and distance ambiguous, the relationship between 
affective and normative distance becomes all the more erratic and nonlinear. Thus, not surprisingly, in contemporary societies we find the most tolerant and the most systematically violent attitudes against strangers side by side. Ours is, no doubt, the age of the most universalistic as well as the most parochial political doctrines.

Inquiring further into the diverse forms that relations with normatively distant groups can take might also have practical implications. Most importantly, it can work as an antidote against two rather naïve and "homogenizing" conceptions of the stranger that are common to both scholarly and popular texts, that is, either as a totally passive sacrificial lamb, the target of unjustifiable and irrational accusations, or as a "potential enemy" with unlimited magical powers for destroying and destabilizing society.

Finally, a few words are in order concerning the broader sociological significance of this analysis. Like most norms, norms of social distance often posit clear-cut distinctions that organize our perception of social reality, provide short-cuts in our relations with others, and make life easier for us. Durkheim (1964) was probably right when he suggested that such norms are the crystallization of long-term emotional investments and that they actually fulfill important functions (Hammond, 1983). However, the fact that many different relations can develop across these normative divisions and that their affective content can show considerable variation implies that these crystallized norms often fail to impose their totalizing perspective on social relations. The practical concerns of the actors involved, their historical memory, their fears and desires, and the technologies they can utilize, among other factors, all shape the relations they form with socially distant (or near) groups and the affections that flow through such relations. If we broadened the analysis here by taking interactive and cultural dimensions of social distance as well, we would most probably observe even further variation and diversity. It might very well be that the possibilities for variation are not endless, but is it not still a worthy task for us to figure out what other possibilities are there?

\section{REFERENCES}

Adorno, T. W., E. Frenkel-Brunswik, D. J. Levinson, and R. N. Sanford. 1950. The Authoritarian Personality. New York: Harper and Brothers.

Arendt, H. 1974. Rahel Varnhagen: The Life of a Jewish Woman. New York: Harcourt Brace Jovanovich.

Balibar, E., and I. Wallerstein. 1991. Race, Nation, Class: Ambiguous Identities. New York: Verso. Bauman, Zygmunt. 1991. Modernity and Ambivalence. Ithaca, NY: Cornell University Press.

Blok, Anton. 1998. "The Narcissism of Minor Differences," European Journal of Social Theory 1: 1: $33-56$.

Bodemann, Y. M. 1993. "Priests, Prophets, Jews and Germans: The Political Basis of Max Weber's Conception of Ethno-National Solidarities," Archives of European Sociology 34: 224-246.

Bogardus, E. S. 1925. "Measuring Social Distances," Journal of Applied Sociology 9: 299-308.

Bogardus, E. S. 1941. Sociology. New York: Macmillan.

Bogardus, E. S. 1947. "Measurement of Personal-Group Relations," Sociometry 10: 4: 306-311. 
Bonacich, E. 1973. "A Theory of Middlemen Minorities," American Sociological Review 38: 583-594.

Bourdieu, P. 1977. Outline of a Theory of Practice. Cambridge: Cambridge University Press.

Bourdieu, P. 1990. "Social Space and Symbolic Power," In P. Bourdieu, In Other Words: Essays Towards a Reflexive Sociology: pp. 122-139. Stanford, CA: Stanford University Press.

Bourdieu, P. 1999. "Site Effects," In P. Bourdieu et al., The Weight of the World: Social Suffering in Contemporary Society: pp. 123-129. Cambridge, UK: Polity.

Cerulo, K. A. 1993. "Symbols and the World System: National Anthems and Flags," Sociological Forum 8: 2: 243-271.

Cerulo, K. A. 1997. "Reframing Social Concepts for a Brave New (Virtual) World," Sociological Inquiry 67: 1: 48-58.

Chancer, L. S. 1992. Sadomasochism in Everyday Life: The Dynamics of Power and Powerlessness. New Brunswick, NJ: Rutgers University Press.

Chayko, M. 2002. Connecting: How We Form Social Bonds and Communities in the Internet Age. Albany, NY: SUNY Press.

Colson, Elizabeth. 1966. "The Alien Diviner and Local Politics Among the Tonga of Zambia," In M. Swartz, V. Turner, and A. Tuden (eds.), Political Anthropology: pp. 221-228. Chicago, IL: Aldine.

Coser, Lewis A. 1972. "The Alien as a Servant of Power: Court Jews and Christian Renegades," American Sociological Review 37: 574-581.

Davis, A. 2000. "Fraternity and Fratricide in Late Imperial China," American Historical Review 105: 5: 1630-1640.

Dawkins, R. 1976. The Selfish Gene. New York: Oxford University Press.

Derrida, J. 2000. Of Hospitality. Stanford, CA: Stanford University Press.

Durkheim, E. 1964. The Division of Labor in Society. New York: Free Press.

Durkheim, E. 1982. The Rules of Sociological Method. New York: Free Press.

Ethington, P. J. 1997. "The Intellectual Construction of 'Social Distance': Toward a Recovery of Georg Simmel's Social Geometry," CyberGeo: European Journal of Geography 30. Retrieved December 8, 2002 (http://www.cybergeo.presse.fr).

Faist, T 2002. "'Extension du domaine de la lutte': International Migration and Security Before and After September 11, 2001," International Migration Review 36: 1: 7-14.

Foucault, M. 1977. Discipline and Punish: The Birth of the Prison. New York: Pantheon.

Freud, S. 1973. "The Uncanny," In The Standard Edition of the Complete Psychological Works of Sigmund Freud. Vol. 17: pp. 217-252. London: Hogarth.

Freud, S. 1985. Civilization, Society and Religion: Group Psychology, Civilization and its Discontents and other Works. Harmondsworth: Penguin.

Girard, René. 1986. The Scapegoat. Baltimore, MD: Johns Hopkins University Press.

Girard, René. 1987. Things Hidden Since the Foundation of the World. London: Athlone Press.

Granovetter, M. S. 1973. "The Strength of Weak Ties," American Journal of Sociology 78: 6: $1360-1380$.

Hammond, Michael. 1983. "The Sociology of Emotions and the History of Social Differentiation," Sociological Theory 1: 90-119.

Hansen, Marcus Lee. 1952. "The Problem of the Third Generation Immigrant," Commentary 14: $492-500$.

Harman, Lesley D. 1988. The Modern Stranger: On Language and Membership. Berlin: Mouton de Gruyter.

Harvey, David. 1989. The Condition of Postmodernity: An Enquiry into the Origins of Cultural Change. Cambridge, MA: Blackwell.

Hechter, Michael. 1978. "Group Formation and the Cultural Division of Labour," American Journal of Sociology 84: 293-318.

Heider, Fritz. 1958. The Psychology of Interpersonal Relations. New York: Wiley.

Helms, Mary W. 1988. Ulysses' Sail: An Ethnographic Odyssey of Power, Knowledge, and Geographical Distance. Princeton, NJ: Princeton University Press.

Homans, George C. 1950. The Human Group. New York: Harcourt, Brace.

Huddy, L., S. Feldman, C. Taber, and G. Lahav. 2005. "Threat, Anxiety, and Support of Antiterrorism Policies," American Journal of Political Science 49: 3: 593-608.

Kadushin, C. 1962. "Social Distance Between Client and Professional," American Journal of Sociology 67: 5: 517-531. 
Karakayali, Nedim. 2005. "Duality and Diversity in the Lives of Immigrant Children: Rethinking the 'Problem of Second Generation' in Light of Immigrant Autobiographies," Canadian Review of Sociology and Anthropology 42: 3: 325-344.

Karakayali, Nedim. 2006. "The Uses of the Stranger: Circulation, Arbitration, Secrecy, and Dirt," Sociological Theory 24: 4: 312-330.

Katz, J. E., and R. E. Rice. 2002. Social Consequences of Internet Use: Access, Involvement, and Interaction. Cambridge, MA: MIT Press.

Kristeva, Julia. 1991. Strangers to Ourselves. New York: Columbia University Press.

Leighton, Neil O. 1979. "The Political Economy of a Stranger Population: The Lebanese of Sierra Leone," In William Shack and Elliott Skinner (eds.), Strangers in African Societies: pp. 85-104. Berkeley, CA: University of California Press.

Levine, Donald N. 1979. "Simmel at a Distance: On the History and Systematics of the Sociology of the Stranger," In William Shack and Elliott Skinner (eds.), Strangers in African Societies: pp. 21-36. Berkeley, CA: University of California Press.

Marsden, P. V., and K. Campbell. 1984. "Measuring Tie Strength," Social Forces 63: 482-501.

Meyrowitz, J. 1997. "Shifting Worlds of Strangers: Medium Theory and Changes in 'Them' Versus 'Us',' Sociological Inquiry 67: 1: 59-71.

Mitamura, T. 1963. Chinese Eunuchs: The Structure of Intimate Politics. Rutland, VT: Charles E. Tuttle.

Park, Robert E. 1924. "The Concept of Social Distance," Journal of Applied Sociology 1: 339-344.

Perin, C. 1988. Belonging in America: Reading Between the Lines. Madison, WI: University of Wisconsin Press.

Poole, W. C. Jr. 1927. “Distance in Sociology,” American Journal of Sociology 33: 1: 99-104.

Räthzel, Nora. 1995. "Images of Heimat and Images of 'Ausländer'," In A. Alund and R. Granqvist (eds.), Negotiating Identities: Essays on Immigration and Culture in Present Day Europe: pp. 45-70. Amsterdam: Rodopi.

Rex, J., and D. Mason (eds.). 1986. Theories of Race and Ethnic Relations. Cambridge, UK: Cambridge University Press.

Sahlins, Marshall D. 1985. Islands of History. Chicago, IL: University of Chicago Press.

Said, Edward W. 1991. Orientalism. London: Penguin.

Schutz, Alfred. 1971. "The Stranger," In Alfred Schutz, Collected Papers, Vol. 2: pp. 91-105. The Hague: Martinus Nijhoff.

Sennett, Richard. 1977. The Fall of Public Man. New York: Knopf.

Simmel, G. 1950. The Sociology of Georg Simmel. New York: Free Press.

Simmel, G. 1955. Conflict and the Web of Group Affiliations. Glencoe, IL: Free Press.

Simmel, G. 1971a. "The Stranger," In Donald N. Levine (ed.), Georg Simmel: On Individuality and Social Forms: pp. 143-150. Chicago, IL: University of Chicago Press.

Simmel, G. 1971b. "Group Expansion and the Development of Individuality," In Donald N. Levine (ed.), Georg Simmel: On Individuality and Social Forms: pp. 251-293. Chicago, IL: University of Chicago Press.

Simmel, G. 1990. The Philosophy of Money. London: Routledge and Kegan Paul.

Szalay, L. B., and B. C. Maday. 1983. "Implicit Culture and Psychocultural Distance," American Anthropologist 85: 1: 110-118.

Tarde, G. 1962. The Laws of Imitation. Gloucester, MA: Peter Smith.

Tocqueville, Alexis de. 2002. Democracy in America. Chicago, IL: University of Chicago Press.

Todorov, Tzvetan. 1993. On Human Diversity. Nationalism, Racism and Exoticism in French Thought. Cambridge, MA: Harvard University Press.

Tuan, Yi-Fu. 1986. "Strangers and Strangeness," Geographical Review 76: 1: 10-19.

van den Berghe, Pierre L. 1987. The Ethnic Phenomenon. Westport, CT: Praeger.

Verkuyten, M., W. de Jong, and C. N. Mason. 1995. "The Construction of Ethnic Categories: Discourses of Ethnicity in the Netherlands," Ethnic and Racial Studies 18: 251-276.

Warner, L. G., and M. L. DeFleur. 1969. "Attitude as an Interactional Concept: Social Constraint and Social Distance as Intervening Variables Between Attitudes and Action," American Sociological Review 34: 2: 153-169.

Weber, Max. 1952. Ancient Judaism. New York: Free Press.

Weber, Max. 1964. The Sociology of Religion. Boston, MA: Beacon.

Weber, Max. 1968. The Religion of India: The Sociology of Hinduism and Buddhism. New York: Free Press. 
Whitehead, David. 1977. The Ideology of the Athenian Metic. Cambridge: Cambridge Philological Society.

Willey, Basil. 1965. The Eighteenth Century Background. Harmondsworth, UK: Penguin Books.

Wilson, Monica. 1979. "Strangers in Africa: Reflections on Nyakyusa, Nguni, and Sotho Evidence," In W. Shack and E. Skinner (eds.), Strangers in African Societies: pp. 51-66. Berkeley, CA: University of California Press.

Wood, Margaret M. 1934. The Stranger: A Study in Social Relationships. New York: Columbia University Press.

Zeitlin, Irving M. 1984. Ancient Judaism: Biblical Criticism from Max Weber to the Present. Cambridge: Polity.

Zerubavel, E. 1993. The Fine Line: Making Distinctions in Everyday Life. Chicago, IL: University of Chicago Press. 